\title{
Female ensoulment: late but durable
}

SIR - John Godfrey ${ }^{1}$ writes with approval of the view expressed by Thomas Aquinas in the thirteenth century that "ensoulment", the becoming of a human person, occurs gradually during embryonic and fetal development. The only point of disagreement is with Aquinas's acceptance of the Aristotelian notion that ensoulment is completed at 40 days in male embryos compared with 90 days in female embryos, which seems an "exotic" error, based on misleading evidence about the development of males and females. I should like to point out, however, that the apparent bizarreness of this idea owes less to embryology than to the extreme reluctance of most present-day molecular biologists to take on board quantitative, as opposed to histological and biochemical, aspects of development, and to consider the importance of time.

A quarter of a century ago, Alfred Jost ${ }^{2}$ stated that the first histological sign of male sexual development (seminiferous tubules) is detectable in human embryos at 6 weeks, and that of female development (primary oocytes) at 11 weeks. More recently it has been shown that male embryos develop faster than female ones right from the beginning ${ }^{3}$, and that male preimplantation cattle embryos have higher metabolic rates than their female counterparts ${ }^{4}$. Human males have higher metabolic rates than females throughout their lifetime ${ }^{5}$, and this could be a reason why males have a shorter life expectancy than females 6 .

Of course, Aristotle was no devotee of equal opportunities. He also had neither a microtome nor a microscope, and in any event would not have known the genetic sex of embryos. The ancient Greek view of the female as a somewhat underdeveloped male would have been based on observed facts, for instance that women have less muscular strength, no beard, and so on, which were interpreted with a good dose of chauvinism. Nevertheless, even if female ensoulment is delayed for 7 weeks, women would seem to be amply recompensed by the expectation that the reverse process of the soul's departure will be delayed by at least 5 years.

\section{Ursula Mittwoch}

Department of Anatomy,

Queen Mary and Westfield College,

London E1 4NS, UK

SIR - Whatever reasons Aquinas had for dating the origin of the human person at 40-60 days after conception, no such reasons are available to those with the benefit of twentieth-century embryology.

The human person is (as Aquinas certainly recognized) an animal of a rational kind, and not a mere 'soul', or life- principle. An animal is a living whole - to be distinguished from a living part, such as a gamete. There is no reason why the living whole should not be seen as originating on completion of sperm entry, when there is first present an entity with the active potential to develop as (not into) an individual human being.

Syngamy is no more than the rearrangement of chromosomes already present in the one-cell embryo. Gene expression is no more than the acting-out of tendencies already present in that embryo. As for the lack of individuality often inferred from the potential to absorb foreign genetic material, if this were a bar to individuality, blood transfusions - not to mention gene therapy - would retrospectively cast doubt on the individuality of the adult human being. As for the possibility of twinning, why should asexual, any more than sexual 'reproduction', be incompatible with the prior existence of the twinning individual?

Once we have identified the embryo as the same individual as the adult human being, we can recognize its interests in fulfilling its potential as the kind of animal it is. While we may have strong emotional grounds for denying that the embryo is a human person, the rational case in favour of this claim is distinctly unconvincing.

\section{Helen Watt}

Linacre Centre,

60 Grove End Road, London NW8 9NH, UK

SIR - While agreeing with Godfrey ${ }^{1}$ that individual identity is acquired gradually and progressively, I am not sure this will help persuade the Pope to alter his advice to Roman Catholics. If one starts from the position that it is sinful to terminate life, there follows a need to define a point at which it begins. Three such points are in current use: fertilization, implantation and neurulation. The Pope (and others, Catholics and the rest) might reason in the face of the developmental continuum described by Godfrey that the safest strategy is to define the earliest possible stage fertilization - as the point at which individuation is set in train. Implantation, when the maternal system begins active support to the conceptus and therefore recognizes its potential viability, is a conceptually well-defined alternative start point. In keeping with this, preimplantation 'contraception' is widely accepted as

1. Godfrey, J. Nature 373. 100 (1995).

2. Jost, A. in Mammalian Reproduction (eds Gibian, H. \& Platz, E. J.) 4-32 (Springer Verlag, Berlin, 1970).

3. Pergament, E., Fiddler, M., Cho, N., Johnson, D. \& Holmgren, W. J. Hum. Reprod. 9, 1730-1732 (1994).

4. Tiffin, G. J., Rieger, D., Betteridge, K. J., Yadav, B. R. \& King, W. J.J. reprod. Fert. 93, 125-132 (1991)

5. Lentner, C. (ed.) Geigy Scientific Tables Vol. 1, 8th edition (Ciba-Geigy, Basle, Switzerland, 1981)

6. Clarke, C. A. \& Mittwoch, U. Persp. biol. Med. 37 327-336(1994) ethically superior to abortion. The use of neurulation to define the onset of personhood may reflect the tendency of Western civilization to identify the brain with the individual. But this stage has the practical advantage that it occurs later, when pregnancy can be recognized by a urine test.

Biologists may differ as to the precise definition of these events, their duration or exactly when they are complete, but they remain conceptually well-defined developmental stages. As far as the lay person is concerned, debating whether fertilization takes a fraction of a second or two days is tantamount to counting the angels on a pinhead.

Godfrey's assumption seems to be that the Catholic Church under Pope John Paul II can be engaged in a debate over reproductive issues. Before this can occur, the church will have to change its attitude to contraception rather than abortion. Given that many Catholics ignore the church on both issues, science should strive to provide them with the means to act in a manner that is increasingly ethically acceptable, as well as being compatible with the realities of unplanned pregnancy and the limited resources of the planet. This means earlier pregnancy diagnosis as well as a greater range of male and female contraceptive options.

\section{John Aplin}

Department of Obstetrics and Gynaecology, University of Manchester,

StMary's Hospital,

ManchesterM130JH, UK

\section{Apoptosis forever}

SIR - Søren Nørby (Nature 372, 312; 1994) wants the second ' $p$ ' in apoptosis silenced "to secure the understanding of the underlying chemistry", with scant regard for the underlying physics of the screw-winged helicopter. Jonathan C. Busser and Alexandra Horowitz compare apoptosis and pterodactyl, to support their contention that "Funder misses an important distinction between pronunciation and spelling". They justify apo' (p)tosis on the grounds that "Because the term used to describe a particular type of cell death is derived from two greek words, apo- and -ptosis, the syllabic break is made between the two words when they are joined".

This is clearly not the case. We say hypoth'esis, but hypo'thetical, breaking the word quite differently where balance and euphony dictate. For consonants the same considerations apply: we pronounce phthisis as tie'sis, but give the similarly greek derived $\phi$ and $\theta$ full play in opthalmologist. Archaeopteryx then, helicopters now, and apoptosis forever.

John Funder

BakerMedical Research Institute, PO Box 348, Prahran 3181, Australia 